\title{
Effect of prior treatments on selinexor, bortezomib, and dexamethasone in previously treated multiple myeloma
}

\author{
Maria V. Mateos ${ }^{1 *}$, Maria Gavriatopoulou², Thierry Facon ${ }^{3}$, Holger W. Auner ${ }^{4}$, Xavier Leleu ${ }^{5}$, Roman Hájek ${ }^{6}$, \\ Meletios A. Dimopoulos ${ }^{7}$, Sosana Delimpasi ${ }^{8}$, Maryana Simonova ${ }^{9}$, Ivan Špička ${ }^{10}$, Luděk Pour ${ }^{11}$, \\ Iryna Kriachok ${ }^{12}$, Halyna Pylypenko ${ }^{13}$, Vadim Doronin ${ }^{14}$, Ganna Usenko ${ }^{15}$, Reuben Benjamin ${ }^{16}$, \\ Tuphan K. Dolai ${ }^{17}$, Dinesh K. Sinha ${ }^{18}$, Christopher P. Venner ${ }^{19}$, Mamta Garg ${ }^{20}$, Don A. Stevens ${ }^{21}$, Hang Quach ${ }^{22}$, \\ Sundar Jagannath ${ }^{23}$, Philippe Moreau ${ }^{24}$, Moshe Levy ${ }^{25}$, Ashraf Z. Badros ${ }^{26}$, Larry D. Anderson Jr. ${ }^{27}$, \\ Nizar J. Bahlis ${ }^{28}$, Michele Cavo ${ }^{29}$, Yi Chai ${ }^{30}$, Jacqueline Jeha ${ }^{30}$, Melina Arazy ${ }^{30}$, Jatin Shah ${ }^{30}$, Sharon Shacham ${ }^{30}$, \\ Michael G. Kauffman ${ }^{30}$, Paul G. Richardson ${ }^{31+}$ and Sebastian Grosicki ${ }^{32+}$
}

\begin{abstract}
Therapeutic regimens for previously treated multiple myeloma (MM) may not provide prolonged disease control and are often complicated by significant adverse events, including peripheral neuropathy. In patients with previously treated MM in the Phase 3 BOSTON study, once weekly selinexor, once weekly bortezomib, and 40 mg dexamethasone (XVd) demonstrated a significantly longer median progression-free survival (PFS), higher response rates, deeper responses, a trend to improved survival, and reduced incidence and severity of bortezomib-induced peripheral neuropathy when compared with standard twice weekly bortezomib and $80 \mathrm{mg}$ dexamethasone (Vd). The pre-specified analyses described here evaluated the influence of the number of prior lines of therapy, prior treatment with lenalidomide, prior proteasome inhibitor (PI) therapy, prior immunomodulatory drug therapy, and prior autologous stem cell transplant (ASCT) on the efficacy and safety of XVd compared with Vd. In this 1:1 randomized study, enrolled patients were assigned to receive once weekly oral selinexor (100 mg) with once weekly subcutaneous bortezomib (1.3 mg/ $\mathrm{m}^{2}$ ) and $40 \mathrm{mg}$ per week dexamethasone (XVd) versus standard twice weekly bortezomib and $80 \mathrm{mg}$ per week dexamethasone (Vd). XVd significantly improved PFS, overall response rate, time-to-next-treatment, and showed reduced all grade and grade $\geq 2$ peripheral neuropathy compared with $\mathrm{Vd}$ regardless of prior treatments, but the benefits of $\mathrm{XVd}$ over Vd were more pronounced in patients treated earlier in their disease course who had either received only one prior therapy, had never been treated with a PI, or had prior ASCT. Treatment with XVd improved outcomes as compared to Vd regardless of prior therapies as well as manageable and generally reversible adverse events. XVd was associated with clinical benefit and reduced peripheral neuropathy compared to standard Vd in previously treated MM. These results suggest that the once weekly XVd regimen may be optimally administered to patients earlier in their course of disease, as their first bortezomib-containing regimen, and in those relapsing after ASCT.
\end{abstract}

\footnotetext{
*Correspondence: mvmateos@usal.es

† Paul G. Richardson and Sebastian Grosicki are co-senior authors

1 Hospital Universitario de Salamanca, Salamanca, Spain

Full list of author information is available at the end of the article
}

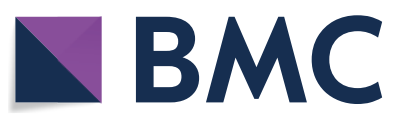

(c) The Author(s) 2021. Open Access This article is licensed under a Creative Commons Attribution 4.0 International License, which permits use, sharing, adaptation, distribution and reproduction in any medium or format, as long as you give appropriate credit to the original author(s) and the source, provide a link to the Creative Commons licence, and indicate if changes were made. The images or other third party material in this article are included in the article's Creative Commons licence, unless indicated otherwise in a credit line to the material. If material is not included in the article's Creative Commons licence and your intended use is not permitted by statutory regulation or exceeds the permitted use, you will need to obtain permission directly from the copyright holder. To view a copy of this licence, visit http://creativecommons.org/licenses/by/4.0/. The Creative Commons Public Domain Dedication waiver (http://creativeco mmons.org/publicdomain/zero/1.0/) applies to the data made available in this article, unless otherwise stated in a credit line to the data. 
Trial registration: ClinicalTrials.gov (NCT03110562). Registered 12 April 2017. https://clinicaltrials.gov/ct2/show/NCT03 110562.

Keywords: Selinexor, Exportin-1, Multiple myeloma, SINE compound

\section{To the Editor,}

Therapeutic options have significantly advanced for patients with multiple myeloma (MM) including combination therapies employing complementary mechanisms or targeting mechanisms distinct from previous regimens $[1,2]$. Selinexor is a first-in-class, orally-available, selective inhibitor of nuclear export (SINE) compound that has shown definitive activity with low dose dexamethasone in patients with triple class refractory MM in the STORM study [3] and synergistic activity with bortezomib and dexamethasone (XVd) in patients with 1-3 prior therapies in the BOSTON study [4]. Here we analyzed pre-specified subpopulations from the BOSTON study to determine the impact of prior lines of therapy and identify those who might optimally benefit from the XVd regimen.

Baseline characteristics were well balanced between treatment arms across subgroups (Additional file 1: Table S1). Median progression-free survival (PFS) was longer on XVd versus Vd in patients with 1 prior line $(P=0.0148)$ or $2-3$ prior lines $(P=0.0295)$, lenalidomide-naïve $(P=0.0150)$ or lenalidomidetreated $(P=0.0177)$ patients, and PI-naïve patients $(P=0.0003)$, with a strong trend in PI-treated patients. Patients with IMiD-refractory MM had a significantly longer median PFS $(P=0.0051)$, as did patients with or without prior ASCT $(P=0.0074$ and $P=0.0341)$. A post-hoc analysis showed a trend towards longer PFS with XVd in patients who received limited bortezomib induction prior to ASCT treatment (Table 1).

Treatment with XVd was associated with a significantly higher overall response rate including patients with 1 prior line, 2-3 prior lines, lenalidomide-naïve or treated, PI-naïve or treated, and prior ASCT (Fig. 1). Subgroups with 1 prior therapy, lenalidomide-naïve, and prior PI treatment had significantly higher rates of $\geq$ VGPR (Additional file 1: Table S2). Median time-to-next-treatment was significantly improved with XVd versus Vd: 1 prior line, 2-3 prior lines, lenalidomide-naïve or treated, PI-naive or treated, and prior ASCT. Across the entire study, overall survival (OS) trended in favor of XVd over Vd (HR, 0.84 [95\% CI 0.57-1.23]; $P=0.19$ ). The median OS for lenalidomide-naïve and PI-naïve patients was not reached, but favored XVd over Vd (HR, 0.76 [95\% CI 0.45-1.29] $P=0.16$ and HR 0.63 [95\% CI $0.25-1.61$ ], $P=0.16$, respectively) (Additional file 1: Table S3).

Overall grade $\geq 3$ adverse events (AEs) occurred more frequently with XVd and were generally well managed. Importantly, grade $\geq 2$ peripheral neuropathy occurred significantly less frequently across all XVd subgroups. The incidence of serious AEs and drug discontinuation due to AEs trended higher with XVd (Additional file 1: Table S4). There was no clear trend regarding AEs leading to a fatal outcome, although the slight excess number of deaths with XVd in the PI-treated subgroup were

Table 1 Progression-free survival by subgroup

\begin{tabular}{|c|c|c|c|c|}
\hline \multirow[t]{2}{*}{ Patients (n, XVd vs Vd) } & \multicolumn{2}{|c|}{ Median PFS, months (95\% Cl) } & \multirow[t]{2}{*}{$\mathrm{HR}(95 \% \mathrm{Cl})$} & \multirow[t]{2}{*}{$P$ value } \\
\hline & $x \vee d$ & $\mathrm{Vd}$ & & \\
\hline 1 prior line (99 vs 99) & $16.62(13.24, N R)$ & $10.68(7.26,16.39)$ & $0.6295(0.4133,0.9586)$ & 0.0148 \\
\hline 2-3 prior lines (96 vs 108) & $11.76(7.39, \mathrm{NR})$ & $9.43(6.83,9.69)$ & $0.6949(0.4760,1.0147)$ & 0.0295 \\
\hline Lenalidomide naïve (118 vs 130) & $16.62(12.98, N R)$ & $10.61(8.44,15.41)$ & $0.6619(0.4548,0.9634)$ & 0.0150 \\
\hline Lenalidomide treated (77 vs 77) & $9.59(6.70, N R)$ & $7.23(4.93,9.69)$ & $0.6348(0.4148,0.9714)$ & 0.0177 \\
\hline PI naïve (47 vs 48) & $N R(N R, N R)$ & $9.69(8.44, N R)$ & $0.2585(0.1116,0.5988)$ & 0.0003 \\
\hline PI treated (148 vs 159) & $11.73(7.95,15.21)$ & $9.43(7.06,10.71)$ & $0.7839(0.5791,1.0612)$ & 0.0576 \\
\hline IMiD refractory (74 vs 86) & $13.93(6.70, N R)$ & $8.44(5.78,9.56)$ & $0.5752(0.3753,0.8816)$ & 0.0051 \\
\hline $\begin{array}{l}\text { Prior bortezomib only as induction for } \\
\text { ASCT ( } 37 \text { vs 30) }\end{array}$ & $13.14(11.73, N R)$ & $9.43(5.75, \mathrm{NR})$ & $0.5807(0.2860,1.1791)$ & 0.0639 \\
\hline ASCT (76 vs 63) & $16.56(9.59, \mathrm{NR})$ & $9.43(5.91,10.87)$ & $0.5527(0.3411,0.8955)$ & 0.0074 \\
\hline No ASCT (119 vs 144) & $13.24(10.18, N R)$ & $9.56(8.11,13.60)$ & $0.7239(0.5111,1.0252)$ & 0.0341 \\
\hline
\end{tabular}




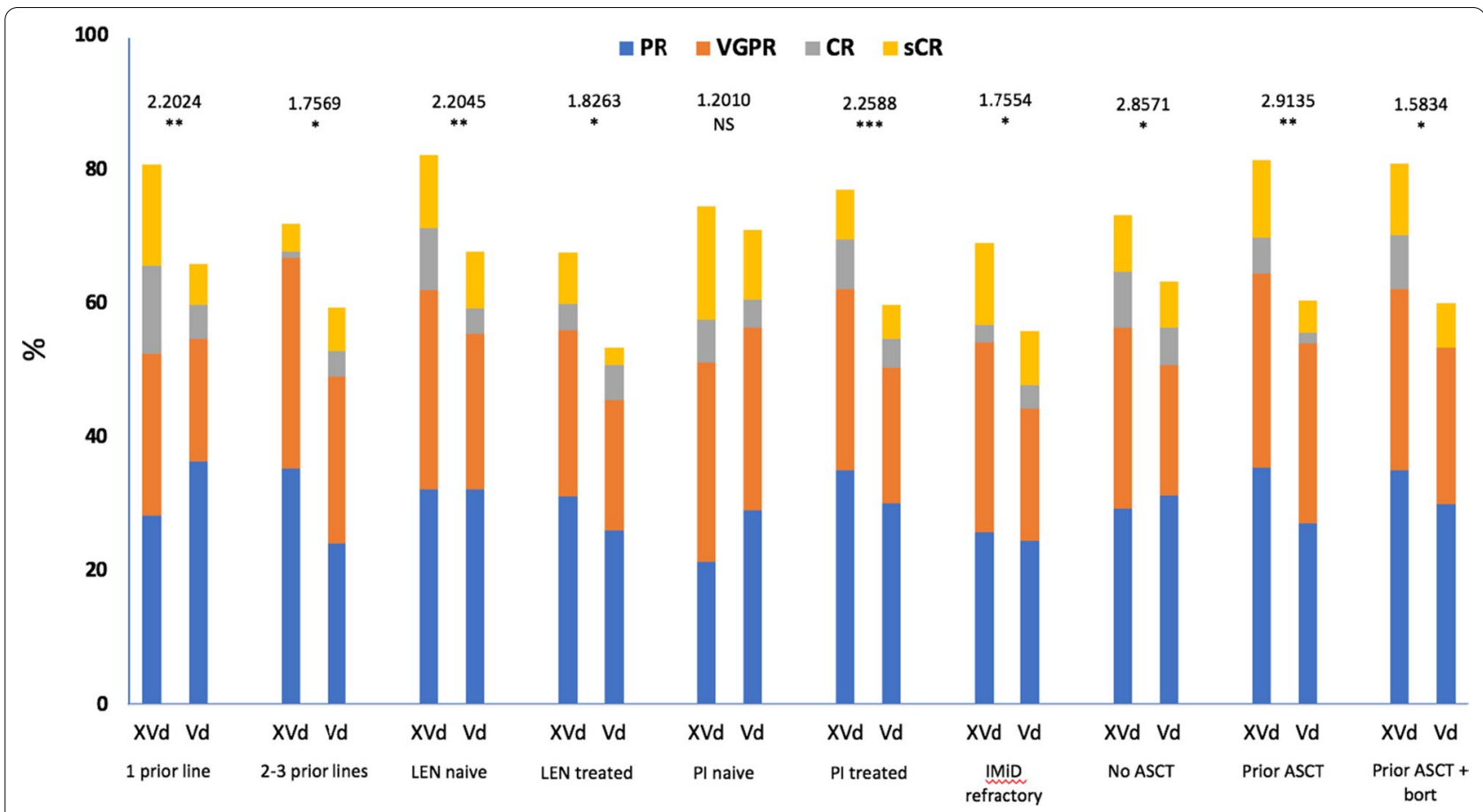

Fig. 1 Depth of response by subgroup and treatment arm. The distribution of response pattern in subgroups based on number of prior lines, lenalidomide (LEN) or proteasome inhibitor (PI) treatment, IMiD refractoriness, and autologous stem cell transplant (ASCT). Bort bortezomib, $C R$ complete response, IMiD immunomodulatory drug, NS not significant, $P R$ partial response, $s C R$ stringent complete response, VGPR very good partial response. Odds ratio and $P$ value shown. ${ }^{*} P<0.05 ;{ }^{*} P<0.01,{ }^{* *} P<0.001$

restricted to India prior to the institution of increased monitoring, after which there were no additional deaths.

Our observations are particularly noteworthy as the once weekly XVd regimen utilizes $\sim 40 \%$ less bortezomib and $25 \%$ less dexamethasone and requires $\sim 37 \%$ fewer clinic visits for bortezomib injections than the standard Vd regimen. Despite the number of additional, subsequent therapies available to patients in this study, allowing patients on $\mathrm{Vd}$ with objective progressive disease to cross-over to a selinexor regimen, and the relatively short follow up, the results were accompanied by favorable trends on OS. Given its unique role in reactivating multiple tumor suppressor proteins and demonstrated synergy with PIs as well as other anti-MM drugs [5-9], these findings are consistent with the use of oral selinexor earlier in the MM treatment course. It is possible that some of the benefits of selinexor in those PI-treated patients may reflect the documented synergy between selinexor and PIs, even cells with marked PI refractoriness [5]. Moreover, benefits in duration and depth of response of XVd over Vd were most pronounced in patients who were PI-naïve, suggesting that selinexor could be an optimal partner for combining with weekly bortezomib as the first PI-containing MM regimen. Moreover, as daratumumab + lenalidomide/ dexamethasone (DRd) is increasingly utilized in frontline MM treatment, the once weekly XVd regimen in second line could lead to a marked reduction in the development of prolonged or permanent bortezomibassociated neuropathy $[10,11]$. Furthermore, the use of XVd following DRd allows for optimal mechanistic switching, thus preserving second generation agents (PIs, IMiDs and anti-CD38 mAbs) for subsequent lines of therapy where they may be more effective $[1,2,12]$.

In conclusion, the earlier use of selinexor in treating MM may provide better, more durable outcomes with lower rates of peripheral neuropathy, using one of the simplest triplet regimens currently available for the treatment of patients with MM [4].

\section{Abbreviations}

ASCT: Autologous stem cell transplant; AE: Adverse event; Cl: Confidence interval; DRd: Daratumumab plus lenalidomide/dexamethasone; HR: Hazard ratio; IMiDs: Immunomodulatory agents; MM: Multiple myeloma; NR: Not reached; ORR: Overall response rate; OS: Overall survival; PD: Progressive disease; PIs: Proteasome inhibitors; PFS: Progression-free survival; PN: Peripheral neuropathy; TTNT: Time-to-next-treatment; $V d$ : Bortezomib dexamethasone; VGPR: Very good partial response; XPO1: Exportin-1; XVd: Selinexor bortezomib dexamethasone. 


\section{Supplementary Information}

The online version contains supplementary material available at https://doi. org/10.1186/s13045-021-01071-9.

Additional file 1. Supplementary material.

\section{Acknowledgements}

JetPub Scientific Communications, LLC supported by funding from Karyopharm, provided drafts and editorial assistance to the authors during preparation of this manuscript.

\section{Authors' contributions}

MVM, MG (Maria Gavriatopoulou), TF, HWA, XL, RH, MAD, SD, MS, IS, LP, IK, HP VD, GU, RB, TKD, DKS, CV, MG (Mamta Garg), DAS, HQ, SJ, PM, ML, AZB, LDA, NJB, MC, YC, JJ, MA, JS, SS, MGK, PGR, SG collected the data. SS, MGK and NJB contributed to the study design. $Y C$ and $J$ J analyzed the data. All authors interpreted the data. All authors edited, and reviewed manuscript drafts, and approved the final version.

\section{Funding}

This study was supported by Karyopharm Therapeutics.

\section{Availability of data and materials}

Karyopharm Therapeutics agrees to share individual participant data that underlie the results reported in this article (after deidentification), including the study protocol and statistical analysis plan. Data availability will begin 9 months after publication and will be available 36 months after publication. To gain access, data requestors should submit a proposal to medicalinformation@karyopharm.com. Proposals will be reviewed by an independent review committee identified for this purpose.

\section{Declarations}

\section{Ethics approval and consent to participate}

The study was approved and performed in accordance with the International Conference on Harmonization, the Guidelines for Good Clinical Practice, appropriate regulatory requirements, and with approval of institutional review boards at individual enrolling institutions. All patients provided written informed consent before study start.

\section{Consent for publication}

\section{Not applicable.}

\section{Competing interests}

M-VM has served as member of advisory boards or received honoraria from Janssen, BMS-Celgene, Takeda, Amgen, Sanofi, Oncopeptides, GSK, Adaptive, Pfizer, Regeneron, Roche and Sea-Gen. MG reports (Maria Gavriatopoulou) receiving honoraria from Amgen, Karyopharm Therapeutics, Takeda, Genesis Pharma, and Janssen-Cilag. TF reports an advisory board role for Karyopharm, Amgen, Roche and Oncopeptides; an advisory board role and a speaker bureau role for Janssen, Celgene/BMS, and Takeda. HWA reports an advisory role for Takeda and Karyopharm; grant from Amgen; and a speaker's bureau role for Janssen. NB reports grants and personal fees from Celgene; personal fees from Janssen, Amgen, Takeda, Abbvie, GSK and Karyopharm. RH has had a consultant or advisory relationship with Janssen, Amgen, Celgene, AbbVie, BMS, Novartis, PharmaMar, and Takeda; has received honoraria from Janssen, Amgen, Celgene, BMS, PharmaMar, and Takeda; has received research funding from Janssen, Amgen, Celgene, BMS, Novartis, and Takeda. IS reports personal fees from Janssen-Cilag, Takeda, Sanofi Aventis and Novartis; personal fees and non-financial support from Colgene, BMS and Amgen. IK reports a consulting role, an advisory role, and a speaker's bureau role for Takeda, Janssen, Roche, Abbvie and MSD; Travel support by Takeda, MSD, Roche, Abbvie and Janssen. CPV has received honoraria from BMS/Celgene, Janssen, Sanofi, Amgen, GSK, and Takeda. MG (Mamta Garg) reports support for attending conferences from Takeda; an advisory role for Amgen, Takeda, Jansen, Novartis and Celgene; and a speaker's bureau role for Janssen. HQ reports grants from and an advisory board role for Amgen, Celgene, Karyopharm, GlaxoSmithKline; non-financial support and research drug supply from Sanofi; an advisory board role for
Janssen Cilag and Specialized therapeutics. SJ reports consulting services for AbbVie, Bristol-Myers Squibb, Janssen Pharmaceuticals, Merck \& Co. PM reports personal fees from Celgene, Amgen, Takeda, Janssen and Abbvie. $\mathrm{ML}$ reports receiving consulting fees and lecture fees from Takeda, Celgene, Seattle Genetics, AbbVie, Jazz Pharmaceuticals, Gilead Sciences, Bristol-Myers Squibb, Amgen, Spectrum Pharmaceuticals, and Janssen. NJB reports grants and personal fees from Celgene; personal fees from Janssen, Amgen, Takeda Abbvie, GSK and Karyopharm.YC, JJ, MA, JS and MGK are employees of and stockholders of Karyopharm. SS reports being employed by and owning stock in Karyopharm Therapeutics, holding patents (8999996, 9079865, 9714226, PCT/US12/048319, and 1574957) on hydrazide-containing nuclear transport modulators and uses, and holding pending patents (PCT/US12/048319, 499/2012, PI20102724, and 2012000928) on hydrazide-containing nuclear transport modulators and uses. PGR reports receiving grant support and honoraria from Oncopeptides, Celgene, and Takeda, grant support from Bristol-Myers Squibb, and honoraria from Amgen, Janssen, and Karyopharm Therapeutics. All other authors declare no competing interests.

\section{Author details}

${ }^{1}$ Hospital Universitario de Salamanca, Salamanca, Spain. ${ }^{2}$ Alexandra Hospital, School of Medicine, National and Kapodistrian University of Athens, Athens, Greece. ${ }^{3}$ CHU Lille Service Des Maladies du Sang, 59000 Lille, France. ${ }^{4}$ Imperial College London, London, UK. ${ }^{5}$ Department of Hematology, CHU La Miletrie and Inserm CIC 1402, Poitiers, France. ${ }^{6}$ Department of Hematooncology, University Hospital Ostrava, Ostrava, Czech Republic. ${ }^{7}$ National and Kapodistrian University of Athens, Athens, Greece. ${ }^{8}$ General Hospital Evangelismos, Athens, Greece. ${ }^{9}$ Institute of Blood Pathology and Transfusion Medicine of NAMS of Ukraine, Lviv, Ukraine. ${ }^{10}$ Charles University and General Hospital, Prague, Czech Republic. ${ }^{11}$ University Hospital Brno, Brno, Czech Republic. ${ }^{12}$ National Cancer Institute, Kiev, Ukraine. ${ }^{13}$ Cherkassy Regional Oncological Center, Cherkassy, Ukraine. ${ }^{14}$ City Clinical Hospital \#40, Moscow, Russian Federation. ${ }^{15}$ City Clinical Hospital No. 4 of Dnipro City Council, Dnipro, Ukraine. ${ }^{16}$ Kings College Hospital NHS Foundation Trust, London, UK. ${ }^{17} \mathrm{Nil}$ Ratan Sircar Medical College and Hospital, Kolkata, India. ${ }^{18}$ State Cancer Institute, Indira Gandhi Institute of Medical Sciences, Patna, India. ${ }^{19}$ Cross Cancer Institute, University of Alberta, Edmonton, AB, Canada. ${ }^{20}$ University Hospitals of Leicester NHS Trust, Leicester, UK. ${ }^{21}$ Norton Cancer Institute, St. Matthews Campus, Louisville, KY, USA. ${ }^{22}$ St Vincent's Hospital, University of Melbourne, Melbourne, VIC, Australia. ${ }^{23}$ Tisch Cancer Institute, Icahn School of Medicine at Mount Sinai, New York, NY, USA. ${ }^{24}$ Hotel-Dieu, University Hospital, Nantes, France. ${ }^{25}$ Baylor University Medical Center, Dallas, TX, USA. ${ }^{26}$ Greenebaum Comprehensive Cancer Center, University of Maryland, Baltimore, MD, USA. 27 Simmons Comprehensive Cancer Center, UT Southwestern Medical Center, Dallas, TX, USA. ${ }^{28}$ Charbonneau Cancer Research Institute, University of Calgary, Calgary, AB, USA. ${ }^{29}$ Seràgnoli Institute of Hematology, Bologna University School of Medicine, Bologna, Italy. ${ }^{30}$ Karyopharm Therapeutics Inc, Newton, MA, USA. ${ }^{31}$ Dana Farber Cancer Institute, Boston, MA, USA. ${ }^{32}$ Medical University of Silesia, Katowice, Poland.

Received: 3 March 2021 Accepted: 29 March 2021

Published online: 13 April 2021

\section{References}

1. Nijhof IS, van de Donk NWCJ, Zweegman S, Lokhorst HM. Current and new therapeutic strategies for relapsed and refractory multiple myeloma: an update. Drugs. 2018;78:19-37.

2. Anderson KC. Progress and paradigms in multiple myeloma. Clin Cancer Res. 2016;22:5419-27.

3. Chari A, Vogl DT, Gavriatopoulou M, Nooka AK, Yee AJ, Huff CA, et al. Oral selinexor-dexamethasone for triple-class refractory multiple myeloma. N Engl J Med. 2019;381:727-38.

4. Grosicki S, Simonova M, Spicka I, Pour L, Kriachok I, Gavriatopoulou M, et al. Once-per-week selinexor, bortezomib, and dexamethasone versus twice-per-week bortezomib and dexamethasone in patients with multiple myeloma (BOSTON): a randomised, open-label, phase 3 trial. Lancet. 2020;396:1563-73.

5. Bahlis NJ, Sutherland $H$, White $D$, Sebag M, Lentzsch S, Kotb R, et al. Selinexor plus low-dose bortezomib and dexamethasone for patients with relapsed or refractory multiple myeloma. Blood. 2018;132:2546-54. 
6. Chari A, Suvannasankha A, Fay JW, Arnulf B, Kaufman JL, Ifthikharuddin JJ, et al. Daratumumab plus pomalidomide and dexamethasone in relapsed and/or refractory multiple myeloma. Blood. 2017;130:974-81.

7. Gasparetto C, Lipe B, Tuchman S, Callander NS, Lentzsch S, Baljevic M, et al. Once weekly selinexor, carfilzomib, and dexamethasone (SKd) in patients with relapsed/refractory multiple myeloma (MM). J Clin Oncol. 2020;38:8530-8530

8. Jakubowiak AJ, Jasielec JK, Rosenbaum CA, Cole CE, Chari A, Mikhael J, et al. Phase 1 study of selinexor plus carfilzomib and dexamethasone for the treatment of relapsed/refractory multiple myeloma. Br J Haematol. 2019;186:549-60.

9. White DJ, Lentzsch S, Gasparetto C, Bahlis N, Chen Cl, Lipe BC, et al. Safety and efficacy of the combination of selinexor, lenalidomide and dexamethasone (SRd) in patients with newly diagnosed multiple myeloma. Blood. 2019;134:3165-3165.

10. Richardson PG, Xie W, Mitsiades C, Chanan-Khan AA, Lonial S, Hassoun H, et al. Single-agent bortezomib in previously untreated multiple myeloma: efficacy, characterization of peripheral neuropathy, and molecular correlations with response and neuropathy. J Clin Oncol. 2009;27:3518-25.

11. Velasco R, Alberti P, Bruna J, Psimaras D, Argyriou AA. Bortezomib and other proteosome inhibitors -induced peripheral neurotoxicity: from pathogenesis to treatment. J Peripher Nerv Syst. 2019;24:S52-62.

12. NCCN Guidelines Insights: Multiple Myeloma, Version 3.2016 in: Journal of the National Comprehensive Cancer Network Volume 14 Issue 4 (2016) [Internet]. [cited 2020 Feb 5]. https://jnccn.org/view/journals/jnccn/14/4/ article-p389.xml

\section{Publisher's Note}

Springer Nature remains neutral with regard to jurisdictional claims in published maps and institutional affiliations.
Ready to submit your research? Choose BMC and benefit from:

- fast, convenient online submission

- thorough peer review by experienced researchers in your field

- rapid publication on acceptance

- support for research data, including large and complex data types

- gold Open Access which fosters wider collaboration and increased citations

- maximum visibility for your research: over $100 \mathrm{M}$ website views per year

At BMC, research is always in progress.

Learn more biomedcentral.com/submissions 